\title{
Hidatidosis ósea: Reporte de 5 casos y revisión de la literatura
}

\author{
OSCAR TAPIA E. ${ }^{1,2}$, AARÓN VIDAL T. ${ }^{3}$, \\ ENRIQUE BELLOLIO J. ${ }^{1,2}$, JUAN CARLOS ROA S. ${ }^{1,2}$
}

'Departamento de Anatomía Patológica. Facultad de Medicina. Universidad de La

Frontera. Temuco, Chile

${ }^{2}$ Scentifical and Technological Bioresources Nucleus (BIOREN)

${ }^{3}$ Servicio de Radiología,

Hospital Hernán Henríquez Aravena; Temuco.

Recibido el 2 de marzo de 2010, aceptado el 27 de septiembre 2010 .

Correspondencia: Dr. Oscar Tapia E. Departamento de Anatomí Patológica, Facultad de Medicina, Universidad de La Frontera. Manuel Montt 112 Fono: 045-296530. Código Postal 478-1176 Temuco, Chile.

E-mail: otescalona@gmail.com

\section{Bone hydatidosis. Report of five patients}

\begin{abstract}
Bone location of hydatid cysts occurs in 0.5 to $3 \%$ of all cases of hydatidosis. The most common bones involved are spine, long bones and pelvis. We report five patients with bone hydatidosis. A 24-year-old male consulting for paraparesis and numbness of lower limbs; CAT scan showed hydatid cysts located in D2, D3 and D4 vertebral bodies. A 47-year-old male consulting for a fracture of the femur; $X$ rays disclosed multiple hydatid cysts in the femur. A 13-year-old female consulting for claudication of the right lower limb; $X$ ray examination showed a hydatid cyst in the iliac bone. A 21-year-old women presenting with weakness of the lower limbs and voiding problems; CAT scan showed a vertebral hydatidosis and spinal cord compression. A 67-year-old female presenting with weakness of the lower limb and loss of sphincter control; CAT scan showed hydatid cysts in D4 vertebral body.
\end{abstract}

(Rev Med Chile 2010; 138: 1414-1421).

Key words: Bone cysts; Echinococcosis; Tomography scanners.

\section{Introducción}

L a hidatidosis es causada por la forma larval del céstodo Echinococcus granulosus y constituye la zoonosis parasitaria más frecuente en Chile; predominando en las áreas ganaderas, especialmente de la zona sur y austral del país. La tasa de incidencia nacional notificada en el año 2004 fue de 2,1 x 100.000 habitantes $^{1-5}$.

En humanos, se han descritos quistes en múltiples localizaciones y número siendo los de localización hepática y pulmonar los más frecuentes ${ }^{6,7}$. Una infrecuente forma de presentación es la hidatidosis ósea, representando entre 0,5\% y $3 \%$ de todos los casos de quistes hidatídicos ${ }^{8-11}$. La distribución de estas lesiones son en columna vertebral 40\%-50\%, huesos largos 25\%-30\%, pelvis 15\%-20\% y más raramente en cráneo, esternón, escápula y falanges ${ }^{11-14}$. Estas lesiones permanecen clínicamente silentes por largo tiempo y en gran parte de los casos el compromiso esá limitado a un sólo hueso o región ósea y excepcionalmente aso- ciado a hidatidosis en otros órganos. La hidatidosis ósea correspondería a una enfermedad de adultos según el momento de presentación clínica, aunque la infección inicial puede ocurrir precozmente en la infancia permaneciendo clínicamente latente hasta por más de 40 años ${ }^{10,11,15-17}$.

De acuerdo a su localización y tiempo de evolución de las lesiones, esta patología se puede diagnosticar por las complicaciones derivadas de ella como son déficit neurológico por compresión medular en casos de localización vertebral, fractura patológica en huesos largos o fistulización e infección secundaria en estadios avanzados con compromiso de partes blandas ${ }^{10,15-17}$.

De acuerdo a lo publicado, el embrión hexacanto llega al hueso por vía hematógena, inicia su transformación vesicular en el tejido óseo esponjoso contenido en su crecimiento por las trabéculas óseas adquiriendo de esta manera un aspecto multivesicular, sin formación de adventicia. Su crecimiento produce atrofia y destrucción del tejido óseo por los siguientes mecanismos: 
efecto mecánico de compresión, aumento de la acción osteoclástica e isquemia por compresión de vasos nutricios y consiguiente necrosis. Una vez que la cortical ósea es erosionada y destruida los quistes invaden tejidos blandos pudiendo llegar a constituir el llamado absceso hidatídico ${ }^{11,17-19}$.

Se presentan cinco casos de pacientes con hidatidosis ósea diagnosticados en la Unidad de Anatomía Patológica del Hospital Hernán Henríquez Aravena de Temuco.

\section{Caso 1}

Hombre de 24 años con residencia rural en la IX región, sin antecedentes mórbidos conocidos. Ingresó al servicio de urgencia luego de sufrir accidente de tránsito de baja energía sin presentar lesiones de consideración secundarias a el. Luego de una semana, consultó por presentar debilidad progresiva de extremidades inferiores, dorsalgia de moderada intensidad y dificultad para orinar. Al examen se constata con hipoestesia bilateral desde nivel D5 hacia distal, paraparesia moderada, hiperreflexia osteotendínea patelar y aquiliana bilateral con signo de Babinski positivo bilateral; se hospitalizó planteándose un trauma raquimedular complicado. El estudio de imágenes con radiografía $(\mathrm{Rx})$ de columna dorsal mostraba aplastamiento de cuerpo D3. La tomografía axial computada (TC) y resonancia nuclear magnética (RM) de columna dorsal demostraron múltiples quistes de tamaño variable en la zona paravertebral derecha que compromete cuerpos vertebrales y elementos posteriores de D2, D3 y D4 e invasión del canal raquídeo junto a imagen de aplastamiento a nivel de D3 compatible con probable etiología hidatídica (Figura 1). Se realizó anamnesis dirigida donde el paciente señaló presentar dorsalgia de tres años de evolución con un episodio de disminución de fuerzas en extremidades inferiores que revirtió

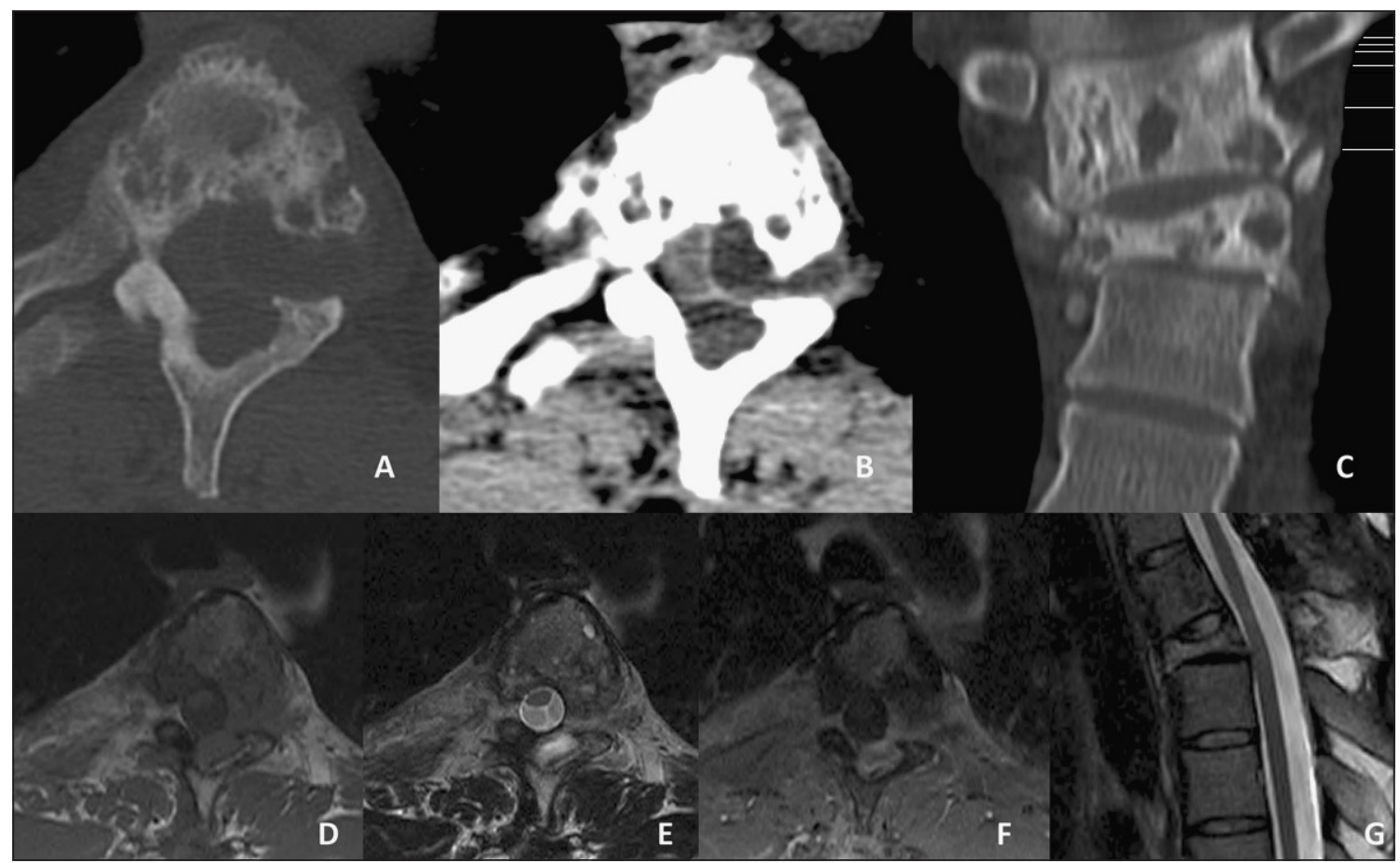

Figura 1. TC: Cortes axiales en ventána ósea (A), ventana de parénquima (B) y coronal óseo (C). Lesión de los cuerpos vertebrales y elementos posteriores D2 y D3 con expansión y destrucción ósea. Quistes subperiósticos secundarios (A). Formación quística con tenue captación periférica del contraste que comprime el saco tecal y expande el agujero de conjunción a izquierda (A y B). Fractura por aplastamiento D3 (C). RM: T1 axial (D), T2 axial (E), T1 GD FS (F) y T2 sagital (G). Lesión expansiva y lítica que compromete cuerpos, pedículos y láminas D2, D3 y D4 con formación secundaria de quistes subperiósticos y posterior invasión del canal raquídeo (D y E). Ligera captación del contraste (F). Aplastamiento del cuerpo vertebral de D3 (G). 
espontáneamente. Los exámenes (hemograma, pruebas de función hepática y renal) no mostraron alteraciones.

Si inició tratamiento con albendazol y realizó hemilaminectomía D3-D4 con exéresis de quistes confirmando el estudio histopatológico el diagnóstico de hidatidosis ósea (Figura 5A).

El paciente evolucionó favorablemente recuperando movilidad completa de extremidades inferiores sin déficit esfinteriano. El estudio con $\mathrm{Rx}$ de tórax y ecografía abdominal no demostraron enfermedad hidatídica diseminada. Completa cuatro ciclos de albendazol.

Luego de tres meses fue nuevamente intervenido quirúrgicamente por absceso dorsal hidatídico y 5 años después por nuevo episodio de paraparesia progresiva con nivel sensitivo en D5 realizándose laminectomía D3-D4 con exéresis de quistes.

\section{Caso 2}

Hombre de 47 años, con residencia rural en la IX región, sin antecedentes mórbidos de importancia. Luego de presentar caída de baja energía golpeándose la extremidad inferior izquierda sufrió fractura supracondílea de fémur. El estudio radiológico demostraba rasgo de fractura en hueso patológico por presencia de múltiples lesiones radiolúcidas en fémur distal compatible con hidatidosis ósea. Se inició tratamiento con albendazol, se realizó curetaje y exéresis de quistes con corrección de rasgo de fractura. El estudio anatomo-patológico confirmó etiología hidatídica (Figura 5B). Se completaron cuatro ciclos de albendazol evolucionado con una consolidación defectuosa y realizándose quince meses después injerto de cresta iliaca. El estudio con ecografía abdominal y Rx de tórax no demostraron lesiones quísticas hidatídicas.

\section{Caso 3}

Mujer de 13 años, con residencia rural en la IX región. Consultó por claudicación derecha progresiva a la marcha destacando en la $\mathrm{Rx}$ de pelvis imagen radiolúcida con bordes escleróticos en ala iliaca derecha planteándose un tumor óseo primario (Figura 2A). La TC de pelvis demostraba una extensa lesión osteolítica con desplazamiento de fragmentos óseos en forma desordenada que comprometía el hueso iliaco derecho y presencia de lesión tumoral de apariencia líquida de hasta 6 $\mathrm{cm}$ de diámetro (Figura 2). Se realizó biopsia de la lesión tumoral dando salida a abundantes membranas blanquecinas hidatídicas junto a líquido transparente tipo agua de roca compatible con hidatidosis pélvica (Figura 5C). Se inició tratamiento con albendazol completando cinco ciclos. El hemograma demostraba aumento de eosinófilos (5\%) y estudio serológico de hidatidosis positivo para IgG y negativo para IgE. Se completó estudio de diseminación con TC cerebral, ecografía de abdomen y Rx de tórax no identificándose lesiones quísticas.

En controles posteriores se encontraba con persistencia del dolor y claudicación con mayor compromiso a la movilidad articular; el estudio de imágenes demostró progresión de la lesión con extensa destrucción ósea. Fue evaluada en Santiago y Argentina por equipos multidisciplinarios considerándose como posibilidad terapéutica una hemipelvectomía. Durante su evolución paciente presentó fiebre y distensión abdominal con ecografía de abdomen que mostraba una masa heterogénea con líquido libre en fosa iliaca derecha compatible con absceso secundario a etiología hidatídica. Se realizó aseo y drenaje quirúrgico e inició tratamiento antibiótico por cultivo positivo para E. coli.

En última TC y RM de pelvis se apreciaron lesiones quísticas alrededor de los vasos iliacos comunes y delante del sacro; el hueso iliaco derecho se encontraba comprometido en su totalidad junto con la articulación sacro-iliaca y coxo-femoral, la porción isquiática de la rama ilio-pubiana esta igualmente afectada por la hidatidosis (Figura 2).

Actualmente la paciente se encuentra con manejo paliativo del dolor y evaluando posibilidad de someterse a la cirugía propuesta.

\section{Caso 4}

Mujer de 21 años, con residencia rural en la IX región hasta la edad de 15 años. Evaluada por cuadro de un mes con dorsalgia, disminución de fuerzas de extremidades inferiores, constipación y dificultad para orinar. Al examen se constató anestesia con nivel D7 hacia distal, reflejos osteotendíneos exaltados, signo de Babinski positivo bilateral planteándose un síndrome espinal anterior con nivel D7. La Rx de columna dorsal mostraba 


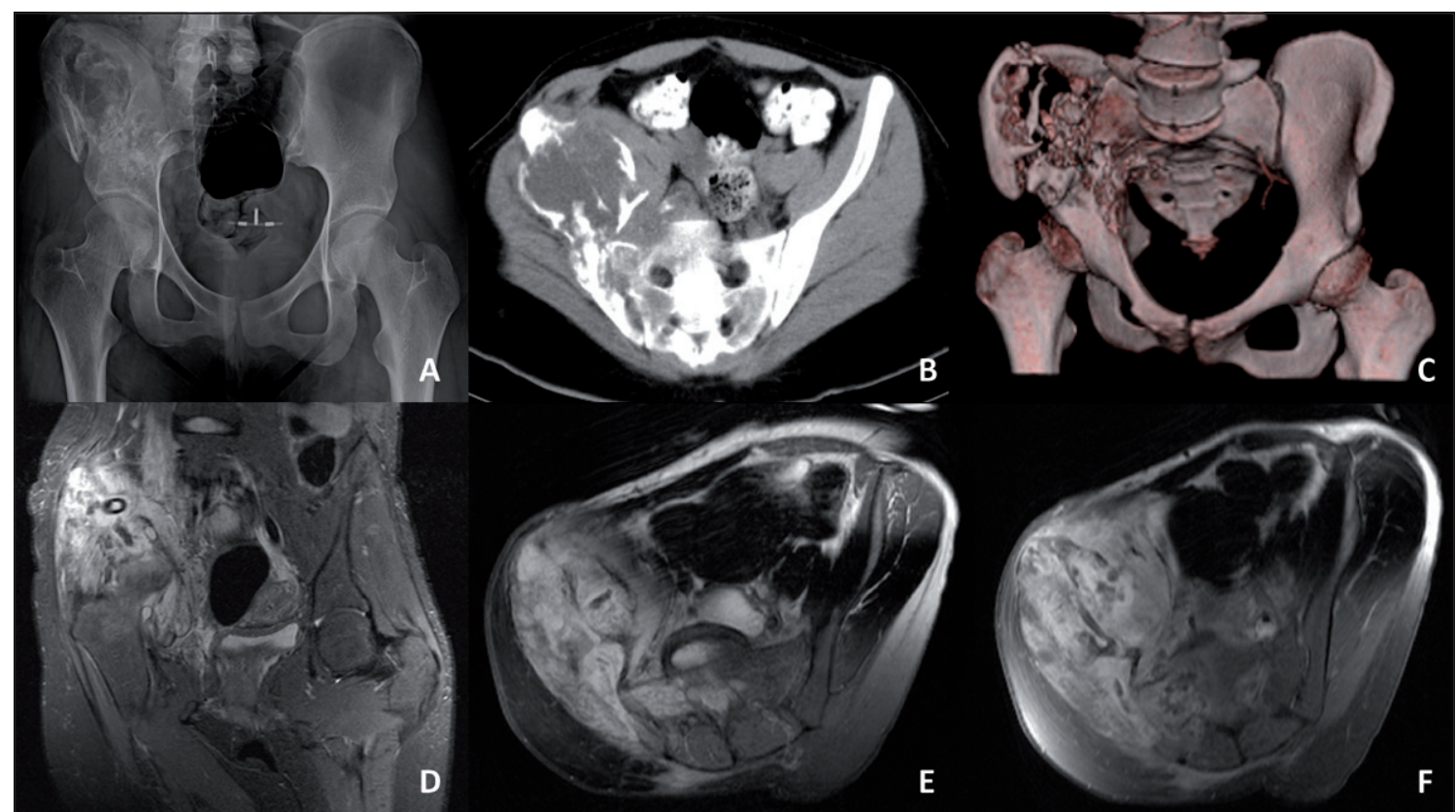

Figura 2. Rx pelvis AP (A). Lesión osteolítica y destructiva del hueso iliaco derecho y acetábulo con márgenes escleróticos irregulares y fractura del ala ilíaca. TC: Corte axial (B) y reconstrucción de pelvis (C). Lesión expansiva osteolítica con epicentro en el ala ilíaca derecha que insufla y destruye el hueso ilíaco y que se extiende parcialmente hacia los tejidos blandos circundantes. RM: T1, STIR coronales (D), T2 axial (E) y T1GD FS axial (F). Extensa lesión expansiva osteolítica multiquística del ala ilíaca, acetábulo, ala sacra, parcialmente de la cabeza femoral y tejidos blandos adyacentes a derecha. Intensa e irregular impregnación preferentemente periférica tras la administración de gadolinio (F).

destrucción de pedículos derechos de D3-D4. En TC de columna dorsal se observaban múltiples lesiones quísticas vertebrales a nivel D3-D4 y una mielografía con importante compresión del saco dural y medular con obliteración del espacio subaracnoídeo y desplazamiento de la medula espinal hacia la izquierda desde el borde superior de D2 al inferior de D4 compatible con hidatidosis vertebral con compromiso intraraquídeo (Figura 3).

Se realizó hemilaminectomía D3-D4 y exéresis de los quistes. El estudio histopatológico concluyó hidatidosis ósea. El hemograma no presentaba alteraciones y el estudio con ecografía abdominal y radiografía de tórax no demuestran quistes en hígado ni pulmón, completando la paciente tres ciclos de albendazol con buena evolución clínica y remisión progresiva de sintomatología neurológica.

Fue nuevamente intervenida en cuatro ocasiones (2, 3, 12 y 13 años posteriores) por presentar paraparesia severa e incontinencia esfinteriana con estudio de imágenes (TC y RM de columna dorsal) que demuestraban lesiones multiquísticas líticas y expansivas a nivel D3 con invasión del canal raquídeo y compresión del saco tecal (Figura 3). Se efectuó aseo quirúrgico con solución hipertónica y laminectomía descrompresiva con resección de cuerpos vertebrales y artrodesis entre D1-D5 completando seis ciclos de albendazol.

Actualmente se encuentra en buenas condiciones, sin déficit neurológico.

\section{Caso 5}

Mujer de 67 años, con residencia rural en la IX región y antecedentes de hidatidosis pulmonar bilateral y hepática operada. Cuadro actual caracterizado por disminución progresiva de fuerzas en extremidades inferiores y pérdida del control esfinteriano de nueve días de evolución. A la anamnesis dirigida la paciente relataba dorsalgia desde hace cuatro meses. Al examen se constató una paraplejia de nivel torácico alto con anestesia táctil y termo-algésica desde nivel de D5 a distal y abolición de reflejos osteotendíneos. Se realizó 


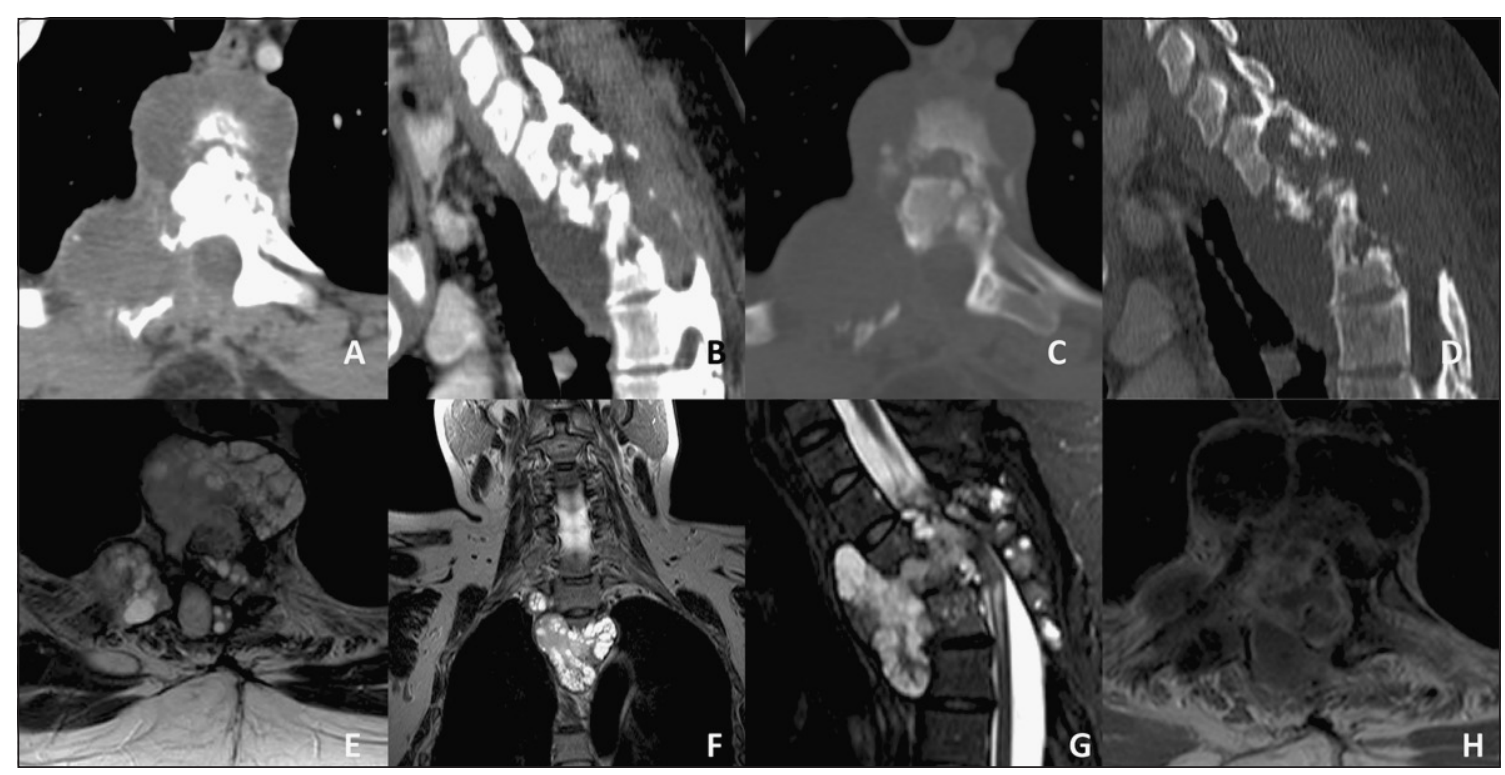

Figura 3. TC: Cortes axial (A) y sagital (B) en ventana de parénquima. Cortes axial (C) y sagital (D) en ventana ósea. Lesión multiquística dorsal expansiva y lítica que compromete elementos anteriores, posteriores y arcos costales. Invasión prevertebral y del canal raquídeo con compresión del saco tecal. RM: T2 axial (E), coronal (F), sagital (G) y T1 axial GD FS (H). Lesión expansiva multiquística $(E, F, G)$ con destrucción y aplastamiento del cuerpo vertebral D3. Compromiso prevertebral, de pedículos, láminas y arco costal derecho. Extensión intrarraquídea, compresión medular y siringomielia $2^{\circ}$. Cifosis secundaria (G). Captación de contraste periférica $(\mathrm{H})$.

TC y RM de columna dorsal que demostraban formaciones quísticas subperiósticas e intraraquídeas con importante compresión del saco tecal a nivel D5 compatibles con probable etiología hidatídica (Figura 4). El hemograma demostraba discreta eosinofilia sin alteraciones de la función hepática ni renal.

Inició tratamiento con albendazol, realizándose laminectomía D6-D7 y exéresis de los quistes. El estudio histopatológico concluyó hidatidosis ósea (Figura 5D). Completó tres ciclos de albendazol. Dado el importante compromiso medular, la paciente no logró recuperación funcional esfinteriana ni músculo-esquelético, encontrándose actualmente en kinesioterapia motora y con cateterismo intermitente.

\section{Discusión}

La hidatidosis ósea corresponde a una entidad poco frecuente ya que las larvas del parásito tienen que penetrar dos filtros antes de alcanzar el hueso: hígado y pulmón; sin embargo, es una de las formas más severas de esta infección ${ }^{8,16}$.
Su distribución más frecuente es a nivel vertebral y en ella la localización torácica con compromiso primario del cuerpo vertebral pudiendo presentar extensión intradural, intramedular y a tejidos blandos paravertebrales; siendo huesos largos (fémur y tibia) y pelvis otras localizaciones frecuentes ${ }^{11,12-14,20}$. De nuestros casos, tres son de localización vertebral y todos ellos de ubicación torácica observándose extensión intraraquidea en todos ellos y compromiso de tejidos blandos en un caso.

Generalmente la enfermedad permanece clínicamente silente durante largos periodos diagnosticándose frecuentemente en adultos, aun cuando la infección ocurre precozmente en la adolescencia. Por esta razón su diagnóstico es generalmente difícil y a menudo se hace cuando las lesiones son extensas, diseminadas o por complicaciones derivadas de ella y un porcentaje no menor solo se diagnóstica después de la cirugía ${ }^{10,11-17,21}$. Las posibles complicaciones derivadas de la hidatidosis ósea consideran fractura patológica en huesos largos, déficit neurológico por compresión medular en hidatidosis vertebral, extensión a tejidos blandos con fistulización y posible sobreinfección 


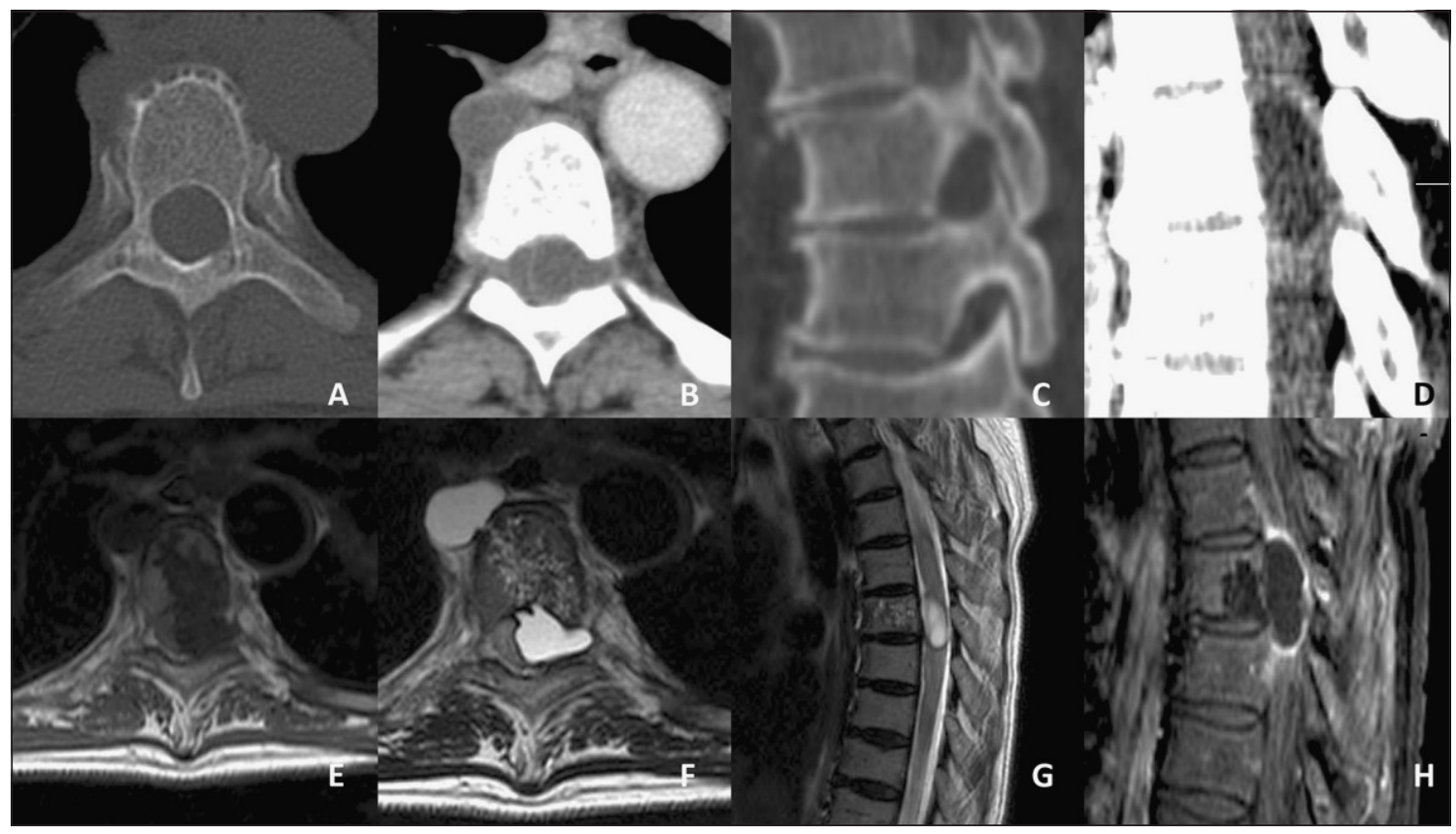

Figura 4. TC: Cortes axiales en ventána ósea (A), ventana de parénquima (B), coronales óseo (C) y en ventana de parénquíma (D). Formaciones quísticas subperiósticas características (A) y formaciones quísticas a nivel prevertebral derecho e intrarraquídea a izquierda la cual comprime el saco tecal y se extiende a través del agujero de conjunción ipsilateral expandiéndolo (B y C). Tenue captación del contraste en la periferia (D). RM: T1 axial (E), T2 axial (F), T2 sagital (G) y T1 sagital GD FS (H). Lesión del cuerpo vertebral D5 (E y F) que infiltra desde su centro a través de las trabéculas con formación secundaria de quistes subperiosticos. Lesiones quísticas que invaden la región prevertebral e intrarraquídea (G) comprimiendo la médula espinal. Captación de gadolinio en la periferia $(H)$.
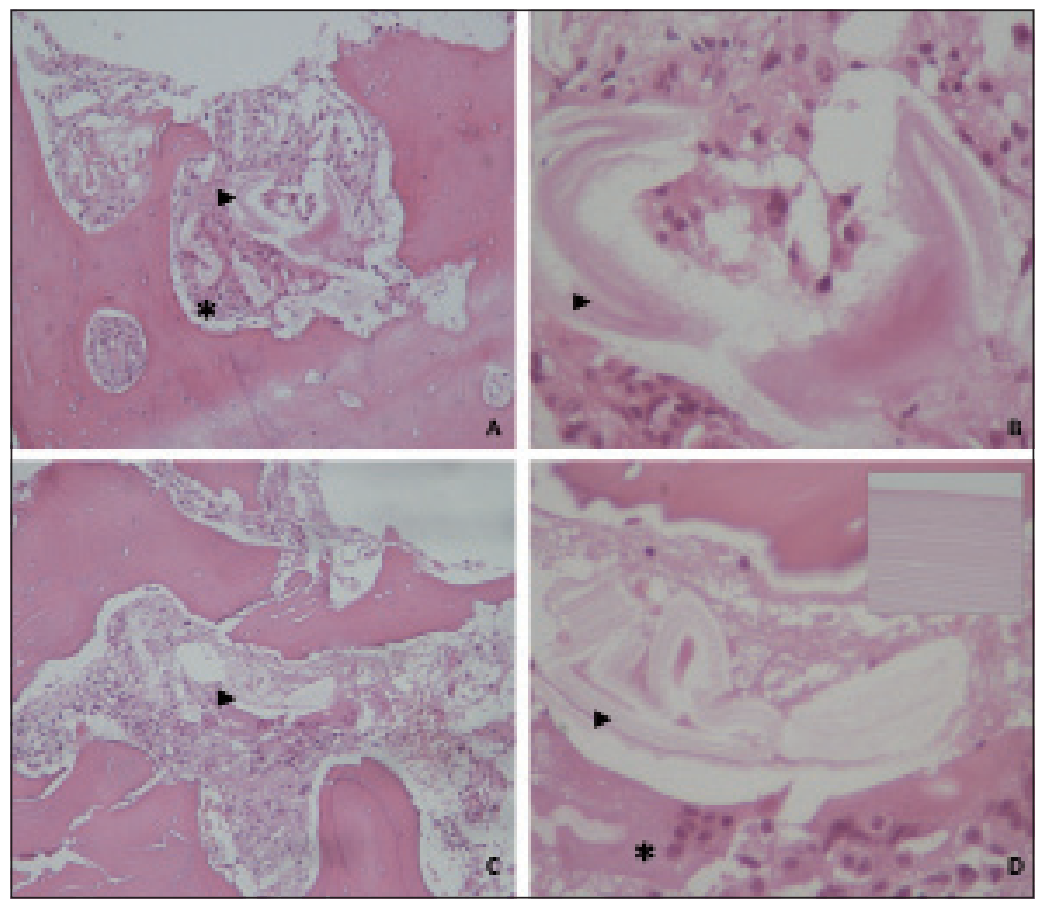

Figura 5. $A(H E, 100 x), B(H E$, 400x), C (HE, 100x) y D (HE, 400x). Se reconoce tejido óseo trabecular con presencia de estructuras laminillares basófilas, acelulares de disposición paralela (membranas hidatídicas) en espacios inter-trabeculares ( $(\mathbf{)})$ e infiltrado inflamatorio predominantemente linfo-histiocitario con formación de células gigantes multinucleadas por reacción a cuerpo extraño $\left(^{*}\right)$. 
bacteriana. Los tres casos de hidatidosis vertebral diagnosticados se manifestaron por compromiso neurológico aparentemente sin sintomatología previa, pero en dos de los cuales la anamnesis dirigida logró identificar la existencia de sintomatología secundaria a la enfermedad vertebral desde hace cuatro meses y tres años.

El estudio por imágenes considera la Rx, TC y RM siendo las dos últimas los métodos de elección para diagnosticar y cuantificar la extensión de las lesiones a tejidos blandos o canal medular y posterior seguimiento de las lesiones una vez tratadas ${ }^{11,21-23}$. Los hallazgos en la Rx simple muestran una lesión osteolítica multilocular, con límites poco claros y ausencia de reacción perióstica, siendo en huesos largos la lesión inicialmente metafisiaria con posterior extensión a epífisis y metáfisis.

La eosinofilia la presentó sólo un paciente, lo que concuerda con lo reportado, describiéndose en tan solo $1 / 4$ de los pacientes con hidatidosis ósea ${ }^{15,16}$.

El tratamiento de elección para la hidatidosis ósea es la extirpación completa de la lesión, sin embarg, en la mayoría de los casos esto no es posible pues se trata de lesiones difusas y extensas en las cuales la terapia eficaz sería mutilante y con secuelas funcionales importantes. En casos de localización pelviana a llegado a plantearse la necesidad de efectuar una hemipelvectomía con conservación del miembro para lograr la exéresis total; en nuestro caso esta posibilidad está siendo evaluada. A pesar de su naturaleza parasitaria, reportes aconsejan tratar esta patología quirúrgicamente bajo criterios oncológicos por su comportamiento localmente destructivo ${ }^{11,16,24-26}$.

En los 5 casos presentados se asoció al tratamiento quirúrgico el uso de antiparasitarios, completando ellos números variables de ciclos; sin embargo, la efectividad del tratamiento farmacológico con antiparasitarios benzoimidazólicos (mebendazol y albendazol) solo o asociado a cirugía es controversial; planteando algunos autores esta posibilidad terapéutica sólo cuando la cirugía no es posible de realizar ${ }^{7,8,10,27,28}$.

Por la alta incidencia de hidatidosis en nuestro país y especialmente en nuestra región, esta patología debe ser considerada dentro de los diagnósticos diferenciales de lesiones óseas tanto tumorales, pseudotumorales como inflamatorias; cada una de ellas con distintas conductas terapéuticas e implicancias pronósticas.

\section{Referencias}

1. Sapunar J. Parasitología Médica. Santiago, Mediterráneo Ltda., 1999; 39: 338-54.

2. Serra I, Araya C, Araneda J. Evolución epidemiológica de la hidatidosis humana en Chile, 1965-1988. Impacto de los programas ganaderos de la XII y XI regiones. Rev Méd Chile 1993; 121: 343-9.

3. Serra I, Araya C, Araneda J. Situación actual de la hidatidosis humana en Chile. Dos proposiciones de corrección de la subnotificación. Rev Méd Chile 1995; 123: 659-69.

4. Serra I, Araneda J, Araya C. Análisis regional de la hidatidosis humana y animal en Chile, 1989-1993. Bol Chil Parasitol 1996; 51: 3-12.

5. Ministerio de Salud de Chile. Enfermedades de Notificación obligatoria. http://www.minsal.cl

6. Noemi I, Benedetto S, Ahumada O. Hidatidosis pediátrica. Parasitol al Día 1991; 15: 108-13.

7. Khiari A, Fabre JM, Mzali R, Domergue J, Beyrouti MI. Unusual locations of hydatid cysts. Ann Gastroenterol Hepatol 1995; 31: 295-305.

8. Agarwal S, Shah A, Khadi SK. Hydatid bone disease of the pelvis: A report of two cases and review of the literature. Clin Orthop 1992; 280: 251-5.

9. Wirbel RJ, Mues PE, Mutschler WE. Hydatid disease of the pelvis and the femur: A case report. Acta Orthop Scand 1995; 66: 440-2.

10. Papanikolaou A. Osseous hydatid disease. Trans R Soc Trop Med Hyg 2008; 102: 233-8.

11. Agulló A, Alcalá-Santaelia A. Hidatidosis muscular. A propósito de tres casos. Rev Esp Reumatol 2002; 29: 44.

12. Col C, Col M, Lafci H. Unusual localizations of hydatid disease. Acta Med Austriaca 2003; 30: 61-4.

13. Schneppenheim M, Jerosch J. Echinococcosis granulosus/cysticus of the tibia. Arch orthop Trauma Surg 2003; 123: 1070111.

14. Tomak Y, Dabak N, Gulman B, Karaismailoglu TN, Basoglu T, Incesu L. Hydatid disease of the left femur: a case report. Bull Hosp Jt Dis 2001-2002; 60: 89-93.

15. Kalinova K, Proichev V, Stefanova P, Tokmakova K, Poriazova E. Hydatid bone disease: a case report and review of the literature. J Orthop Surg 2005; 13: 323-5.

16. Zlitni M, Ezzaouia K, Lebib H, Karray M, Kooli M, Mestiri M. Hydatid cyst of bone: diagnosis and treatment. World J Surg 2001; 25: 75-82.

17. Sapunar J, Velasco M. Hidatidosis del omóplato con localización extraósea. Bol Chil Parasitol 2000, 55: 3-4.

18. Sapunar J, Bahamonde L. Hidatidosis del húmero complicada con fractura, infección bacteriana, fístula y localización extraósea. Bol. Chil. Parasitol 1995; 50: 37 41. 
19. Fernández L. Hidatidosis Ósea. Tratado de Patología y Clínica Quirúrgicas, editado por Durán Sacristán H. et al. pp. 3636-3642. Interamericana-McGraw Hill, Madrid, 1996.

20. Braithwaite PA, Lees RF. Vertebral hydatid disease: radiological assessment. Radiology 1981; 140: 763-6.

21. Morris BS, Madiwale CV, Garg A, Chavhan GB. Hydatid disease of bone: a mimic of other skeletal pathologies. Australas Radiol 2002; 46: 431-4.

22. Markonis A, Tavernaraki A, Papaevangelou M. Humeral hydatid cyst complicated with extraosseous involvement: a case of unusual location of echinococcosis. Eur J Radiol 2001; 37: 130-3.

23. Gelabert-Gonzales M. Compresión medular por quiste hidatídico vertebral. Rev Neurol 2000; 30: 654-5.
24. Gorun N. Necessary hip disarticulation in extended echinococcosis of the femur. Rev Chir Orthop Reparatrice Appar Mot 1992; 78: 255-7.

25. Saenko AI. Amputatio interilioabdominalis for echinococcosis of the hip and pelvis. Khirurgiia 1965; 41: 132-3.

26. Santavirta S. Disseminated hydatid disease causing paraplegia and destruction of the hip. Arch of orthopeadic \& Trauma surg 2000; 120: 118-20.

27. WHO informal Working Group on Echinococcosis. Guidelines for treatment of cystic and alveolar echinococcosis in humans. WHO bulletin OMS 1996; 4: 231-42.

28. Szypryt EP, Morris DL, Mulholland RC. Combined chemotherapy and surgery for hydatid bone disease. J Bone Joint Surg 1987; 69B: 141-4. 